\title{
Critical load of steel trusses - graphical methods
}

\author{
Piątkowski Micha1 ${ }^{1, *}$ \\ ${ }^{1}$ Koszalin University of Technology, Faculty of Civil Engineering, Environmental and Geodetic \\ Sciences, Śniadeckich 2, 75-453 Koszalin, Poland
}

\begin{abstract}
The article presents graphical methods for determine critical loads of column and beam elements based on experimental results. The author presents the principles of using each method and the results of author's experimental tests on the instability phenomenon of planar steel truss with imperfections. The discussed methods were used to determine critical load of the tested truss, next compared with the results of numerical analysis. The validity of methods for determining the critical moment in the truss analysis has been confirmed.
\end{abstract}

\section{Introduction}

Knowledge of the critical load of compressive and flexural elements is important in the case of design considering global stability of structures: buckling and lateraltorsional buckling [1]. This load can be determined using empirical formulas, e.g. Euler formula, or computer programs, e.g. LT-Beam.

The critical load can also be determined experimentally [2]. However, experimental models always are imperfect structures whose equilibrium paths are characterized by limit points rather than bifurcation points [3]. The equilibrium path of the imperfect systems (formula 1a) are characterized by the critical load, which is the horizontal asymptotes and the initial imperfections that affect of the non-linear relationships between load and displacements [4] (figure 1c).

Experimental determination of the critical load of compressed elements is related to the transformation of Southwell, which converts the formula (1a) to the linear form (formula $1 \mathrm{~b}$ ). This function, in the coordinate system $(\delta / P ; \delta)$, intersects the vertical axis in the point, which is the initial imperfection $\left(-\mathrm{e}_{0}\right)$, while the tangent of its $\alpha$ angle is the critical force of the elements (figure 2.).

$$
\delta=\frac{e_{0}}{\frac{P_{c r}}{P}-1} ; \delta=\frac{\delta}{P} P_{c r}-e_{0}
$$

where:

$\delta \quad$ transverse displacement of the compressed element,

\footnotetext{
*Corresponding author: michal.piatkowski@tu.koszalin.pl
} 
$e_{0} \quad$ initial imperfection,

$P_{c r} \quad$ critical load of a perfect element,

$P \quad$ real compressive load.

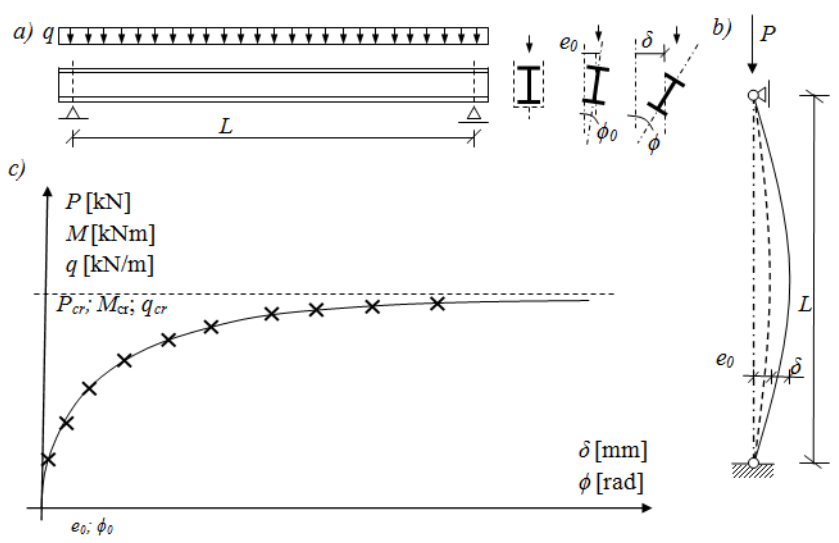

Fig. 1. Imperfect elements: a) beam; b) column; c) equilibrium path.

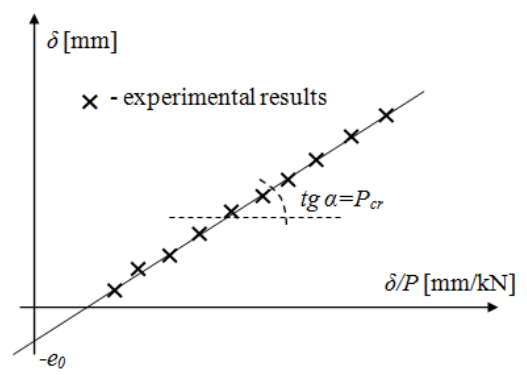

Fig. 2. Southwell's Method.

Similar rules relate to the experimental determination of the critical moment of bending elements. These elements are assumed with initial "out-of-straightness" imperfections $e_{0}$ and initial torsional imperfection $\phi_{0}$. The increment of the twist angle $\phi$ in the beam is analogous to the increase of deformation $\delta$ in the compression element and can be expressed by the formula [3]:

$$
\phi=\frac{\phi}{M} M_{c r}-\phi_{0}
$$

where:

$\phi \quad$ angle of torsional deformation,

$\phi_{0} \quad$ initial torsional deformation,

$M_{c r} \quad$ critical moment of bending beam,

M max. moment.

\section{Methods to determine the critical moments}

Initial attempts to use the Southwell method in the analysis of experimental data of bending beams showed a good agreement between the slope of the line and the empirically determined critical moment [5]. In the 20th century, many researchers proposed their own modifications of the graphic method, e.g.:

- Massey (1963), 
- Trahair (Modified Plot - 1969),

- Meck (Skewed Plot - 1977).

These methods employ the different coordinate systems and different forms of equations (1b) and (1c). The Massey's method should be used for beams at bending with a single initial imperfection $e_{0}$ or $\phi_{0}$ [5]. The Massey's plots are constructed in the coordinate system $\left(\delta / M^{2} ; \delta\right)$ or $\left(\phi / M^{2} ; \phi\right)$, while the critical moment (or critical load) is the square root of the slope angle of the straight line (2a) or (2b). This method involves linear equations in the form of:

$$
\delta=\sqrt{M_{c r}} \frac{\delta}{M^{2}}-e_{0} ; \phi=\sqrt{M_{c r}} \frac{\phi}{M^{2}}-\phi_{0}
$$

The Trahair's modification rely on transforming the formulas (1b) and (1c) into the form:

$$
\delta \cdot M=\delta \cdot M_{c r}-\delta_{0} \cdot M ; \phi \cdot M=\phi \cdot M_{c r}-\phi_{0} \cdot M
$$

This transformation, called Modified Plot, creates a straight line in the coordinate system $(\delta ; \delta M)$, whose angle of inclination is a critical moment, unfortunately it doesn't give a graphical representation of the initial imperfections in an obvious way [6].

The last variant of the graphical method, discussed in this paper, is called "Skewed Plot" due to the specific coordinate system, in which the lateral displacement and the twisting of the cross-section occur simultaneously.

$$
\delta=\alpha \frac{\phi}{M}-\delta_{0} ; \phi=\beta \frac{\delta}{M}-\phi_{0}
$$

where:

$$
\begin{array}{ll}
\alpha=\frac{\pi^{2} \cdot E J}{L^{2}} ; \beta=G \cdot J_{T} \\
E & \text { modulus of elasticity, } \\
J & \text { second moment of area - weak axis } \\
L & \text { length of elements, } \\
G & \text { shear modulus, } \\
\mathrm{J}_{\mathrm{T}} & \text { second polar moment of area. }
\end{array}
$$
formula:

In this method, the critical load is calculated on the basis of both plots according to the

$$
M_{c r}=\sqrt{\alpha \cdot \beta}
$$

The work of planar trusses are resembles the work of beams at bending (truss is a kind of beams with a castellated web). The experimental determination of the critical load of the compression chord in this elements can be done by different ways: using the equilibrium path of a separate chord (applying the Southwell method); or using the equilibrium path of an entire truss (by the Southwell or Meck method). Typically, in experimental studies, the critical load is firstly determined and next the critical force or critical moment are calculated. It should be noted that the use of the equilibrium path of a separate compression chord does not allow to determine initial imperfections of an entire truss $\left(e_{0} \mathrm{i} \phi_{0}\right)$, instead a certain overall imperfection only.

In the experimental tests an external critical load is usually determined. Next the critical force of the compression element or the critical moment of the bending element 
is determined based on the known critical load value. The stability problem in beam elements is well recognized and described, e.g. in [7].The relationship between the critical moment $M_{c r}$ of the bending I-beam and the critical force $N_{c r}$ of the compression chord was presented in the paper [8]. The literature also includes information on equivalent truss models in the analysis of bending I-beams [9]. Thus there is an analogy between buckling of the upper truss chord and lateral-torsional buckling of the bending beam.
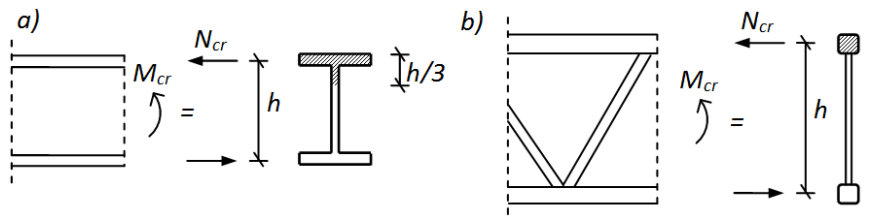

Fig. 3. Relation between the critical moment of the beam and the critical force of the compression chord: a) I-beam; b) truss.

\section{Experimental research}

Comparison of graphical methods for determining the critical moment in planar trusses was carried out on the results of author's experimental research. That research concerned seven meter long research models shown in Figure 4. The tests were carried out on simply supported single-span models with lateral, rigid support at the ends of the chords. At the beginning of the tests, the measurement was made of real, initial out-of-plane imperfections in the state without external load. During the study, the gravitational load was applied gradually in the nodes of the upper chord. The tests were carried out in the elastic range, limiting the possible deformation of chords up to $150 \mathrm{~mm}$. The research models were made of steel with declared yield point of $f_{y}=235 \mathrm{MPa}$. The results of experimental tests, in the form of horizontal displacements of the upper and bottom chords, relative to the measured initial imperfections, are presented in Table 1 . The displacements were measured at the chord nodes using inductive displacement sensors with a range of $300 \mathrm{~mm}$ and an accuracy of $0.001 \mathrm{~mm}$.

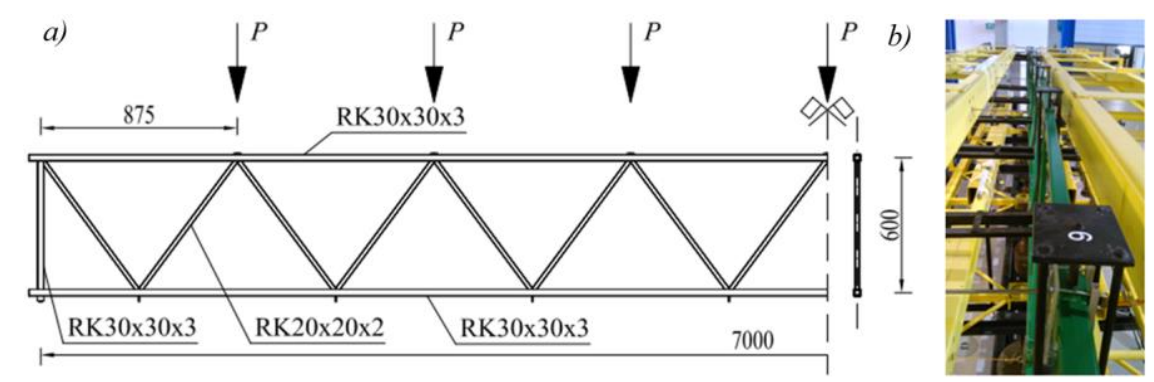

Fig. 4. Research model: a) scheme; b) Lateral-torsional buckling of a truss.

The research studies included also determination of the impact of various, simultaneous systems of chord imperfections on the equilibrium path of the truss. These configurations, e.g. opposite chord imperfections, were induced by means of an additional lateral load. The tests showed a significant effect of the imperfection of the tension chord on the shape of the equilibrium path of the compression chord and therefore also on the limit load on the truss [10]. The article presents only the basic results of experiment obtained for imperfect models without forcing any special imperfection configurations. 
For the considered static scheme, the relationship between the load and the maximum bending moment of the equivalent beam can be expressed in the following form (this same is true for critical load and critical moment):

$$
M_{\text {max }}=L \cdot P
$$

Table 1. Experimental results.

\begin{tabular}{|c|c|c|c|c|c|c|}
\hline \multirow[b]{2}{*}{$\begin{array}{c}\text { Nodal load } \\
\mathrm{P} \\
{[\mathrm{kN}]}\end{array}$} & \multicolumn{2}{|c|}{ Model 1} & \multicolumn{2}{|c|}{ Model 2} & \multicolumn{2}{|c|}{ Model 3} \\
\hline & $\begin{array}{c}\text { upper } \\
\text { chord } \\
\text { (comp.) } \\
\delta_{\mathrm{u}} \\
{[\mathrm{mm}]}\end{array}$ & $\begin{array}{c}\text { bottom } \\
\text { chord } \\
\text { (tension) } \\
\delta_{b} \\
{[\mathrm{~mm}]}\end{array}$ & $\begin{array}{c}\text { upper } \\
\text { chord } \\
\text { (comp.) } \\
\delta_{\mathrm{u}} \\
{[\mathrm{mm}]}\end{array}$ & $\begin{array}{c}\text { bottom } \\
\text { chord } \\
\text { (tension) } \\
\delta_{\mathrm{b}} \\
{[\mathrm{mm}]}\end{array}$ & $\begin{array}{c}\text { upper } \\
\text { chord } \\
\text { (comp.) } \\
\delta_{\mathrm{u}} \\
{[\mathrm{mm}]}\end{array}$ & $\begin{array}{c}\text { bottom } \\
\text { chord } \\
\text { (tension) } \\
\delta_{\mathrm{b}} \\
{[\mathrm{mm}]}\end{array}$ \\
\hline $\begin{array}{c}\mathrm{e}_{0 . u} ; \mathrm{e} 0 . \mathrm{b} \\
\text { initial } \\
\text { imperfection } \\
\text { (middle of } \\
\text { chord) }\end{array}$ & 4.803 & 1.203 & 5.399 & 3.304 & 10.412 & 9.711 \\
\hline 0 & 0 & 0 & 0 & 0 & 0 & 0 \\
\hline 0.20 & 0.024 & 0.060 & 0.438 & 0.223 & 0.101 & 0.015 \\
\hline 0.40 & 3.853 & 1.050 & 2.871 & 1.731 & 1.444 & -0.572 \\
\hline 0.60 & 8.271 & 4.173 & 10.279 & 6.933 & 5.217 & 1.1815 \\
\hline 0.65 & 11.605 & 6.582 & 12.957 & 8.835 & 6.717 & 2.072 \\
\hline 0.70 & 14.623 & 8.500 & 17.410 & 11.947 & 10.071 & 4.379 \\
\hline 0.75 & 18.284 & 11.261 & 24.741 & 17.170 & 14.722 & 7.524 \\
\hline 0.80 & 25.281 & 16.249 & 34.758 & 24.100 & 20.057 & 11.085 \\
\hline 0.82 & 31.504 & 20.558 & 39.746 & 27.424 & 23.577 & 13.754 \\
\hline 0.84 & 37.410 & 24.740 & 45.217 & 31.086 & 28.369 & 16.692 \\
\hline 0.86 & 42.855 & 28.413 & 53.474 & 36.752 & 33.364 & 19.332 \\
\hline 0.88 & 53.036 & 35.408 & 60.566 & 41.475 & 39.842 & 23.957 \\
\hline 0.90 & 61.637 & 41.264 & 77.964 & 53.598 & 46.099 & 28.441 \\
\hline 0.92 & 69.766 & 46.502 & 96.275 & 66.020 & 57.653 & 35.975 \\
\hline 0.94 & 89.142 & 59.994 & 132.429 & 91.225 & 69.688 & 43.888 \\
\hline 0.96 & - & - & - & - & 106.986 & 68.567 \\
\hline
\end{tabular}

On the basis of the obtained results, general deformation of the entire truss was determined: horizontal displacement $\delta_{\text {truss }}$ and rotation $\phi$ in accordance with Fig. $5 \mathrm{~b}$. These results are summarized in Table 2.
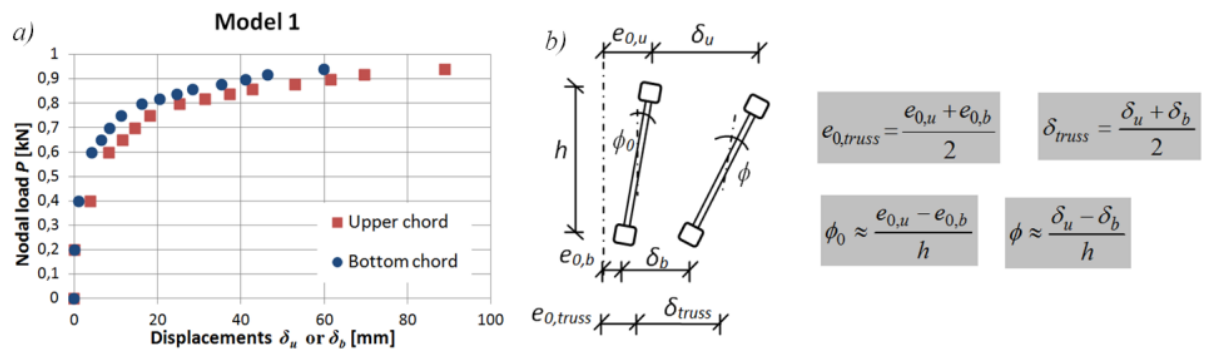

Fig. 5. Measured chord deformations: a) equilibrium path of the chords - Model 1; b) the calculating method of the truss deformation. 
Table 2. Deformation of truss.

\begin{tabular}{|c|c|c|c|c|c|c|c|}
\hline \multirow{2}{*}{$\begin{array}{c}\text { Nodal } \\
\text { load P } \\
{[\mathrm{kN}]}\end{array}$} & $\begin{array}{c}\text { Moment } \\
(\text { form. 4) } \\
{[\mathrm{kNm}]}\end{array}$ & \begin{tabular}{c} 
Model 1 \\
\cline { 3 - 8 } \\
ents $\delta_{\text {truss }}$
\end{tabular} & $\begin{array}{c}\text { Rotation } \\
\phi[\mathrm{mm}]\end{array}$ & $\begin{array}{c}\text { Displacem } \\
\text { ents } \delta_{\text {truss }} \\
{[\mathrm{mm}]}\end{array}$ & $\begin{array}{c}\text { Rotation } \\
\phi[\mathrm{rad}]\end{array}$ & $\begin{array}{c}\text { Displacem } \\
\text { ents } \delta_{\text {truss }} \\
{[\mathrm{mm}]}\end{array}$ & $\begin{array}{c}\text { Rotation } \\
\phi[\mathrm{rad}]\end{array}$ \\
\hline \multicolumn{2}{|c|}{$\begin{array}{c}\text { initial imperfection } \\
e_{0, \text { truss }} ; \phi_{0}\end{array}$} & 3.003 & 0.006 & 4.352 & 0.0035 & 10.062 & 0.0012 \\
\hline 0 & 0.00 & 0.000 & 0.000 & 0.000 & 0.0000 & 0.000 & 0.0000 \\
\hline 0.20 & 1.40 & 0.077 & 0.00016 & 0.331 & 0.0004 & 0.058 & 0.0001 \\
\hline 0.40 & 2.80 & 2.452 & 0.00467 & 2.301 & 0.0019 & 0.436 & 0.0034 \\
\hline 0.60 & 4.20 & 6.222 & 0.00683 & 8.606 & 0.0056 & 3.199 & 0.0067 \\
\hline 0.65 & 4.55 & 9.094 & 0.00837 & 10.896 & 0.0069 & 4.395 & 0.0077 \\
\hline 0.70 & 4.90 & 11.562 & 0.01021 & 14.679 & 0.0091 & 7.225 & 0.0095 \\
\hline 0.75 & 5.25 & 14.773 & 0.01171 & 20.956 & 0.0126 & 11.123 & 0.0120 \\
\hline 0.80 & 5.60 & 20.765 & 0.01505 & 29.429 & 0.0178 & 15.571 & 0.0150 \\
\hline 0.82 & 5.74 & 26.031 & 0.01824 & 33.585 & 0.0205 & 18.666 & 0.0164 \\
\hline 0.84 & 5.88 & 31.075 & 0.02112 & 38.152 & 0.0236 & 22.531 & 0.0195 \\
\hline 0.86 & 6.02 & 35.634 & 0.02407 & 45.113 & 0.0279 & 26.348 & 0.0234 \\
\hline 0.88 & 6.16 & 44.222 & 0.02938 & 51.021 & 0.0318 & 31.900 & 0.0265 \\
\hline 0.90 & 6.30 & 51.451 & 0.03396 & 65.781 & 0.0406 & 37.270 & 0.0294 \\
\hline 0.94 & 6.44 & 58.134 & 0.03877 & 81.148 & 0.0504 & 46.814 & 0.0361 \\
\hline 0.94 & 6.58 & 74.568 & 0.04858 & 111.827 & 0.0687 & 56.788 & 0.0430 \\
\hline 0.96 & 6.72 & - & - & - & - & 87.777 & 0.0640 \\
\hline
\end{tabular}

\section{Critical moment of a planar truss}

The numerically determined critical loadvalue of the researched structure is $0.971 \mathrm{kN}$. This load was determined in the SOFiSTiK program by means of linear buckling analysis (LBA) [11]. Numerical analysis was performed on a perfect model with nominal material and cross-section characteristics. The critical force in the compression chord corresponding to the critical load is $11.3 \mathrm{kN}$, while the appropriate buckling length factor is $\mu=0.374$.

Based on the values summarized in Tables 1st and 2nd selected plots were developed.
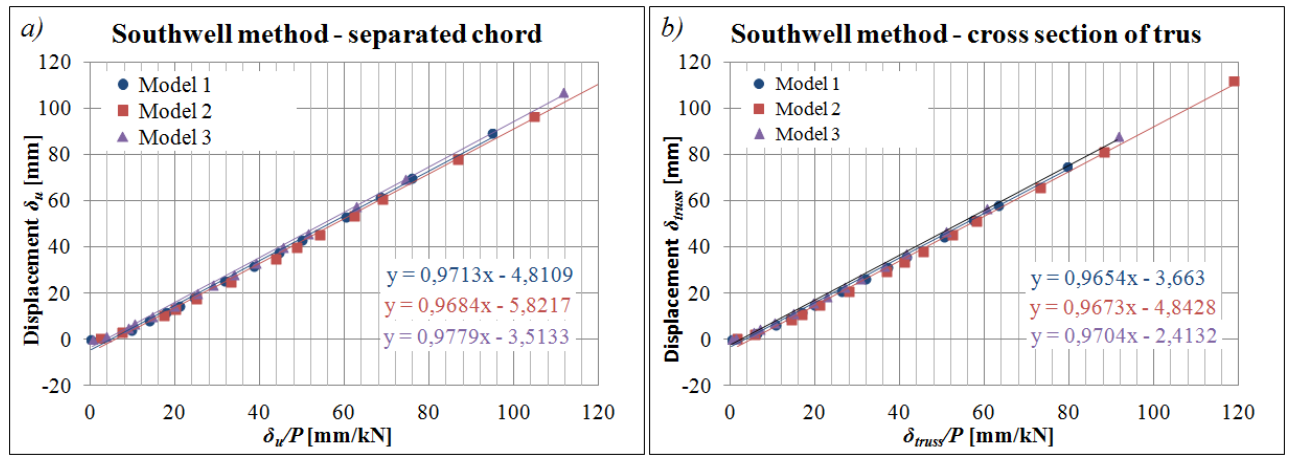

Fig. 6. Graphical results of the Southwell method (all models): a) for the separated upper chord; b) for the whole truss. 

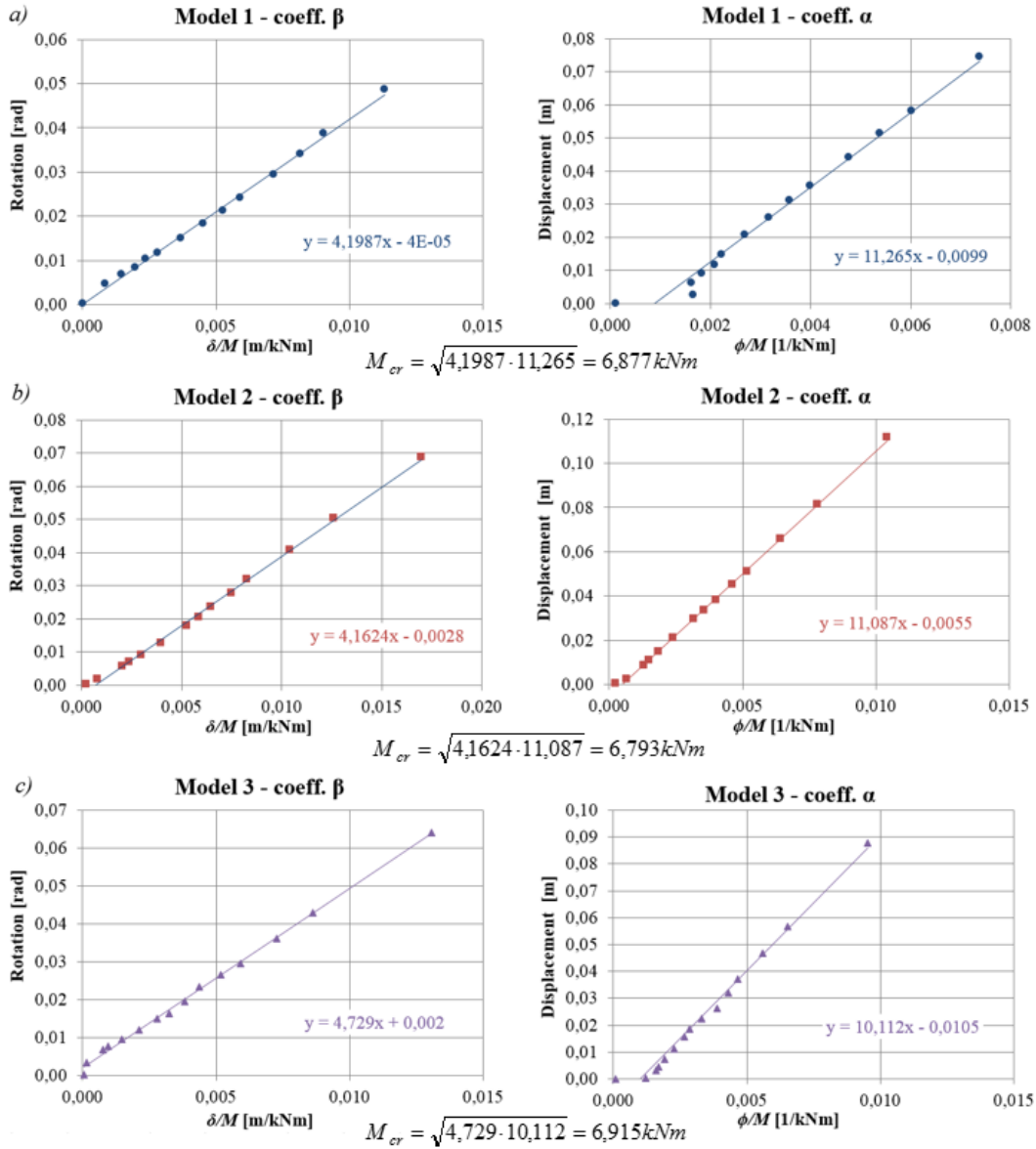

Fig. 7. Graphic results of the Meck method: a) Model 1; b) Model 2; c) Model 3.

The critical loads obtained on the basis of the values from the diagrams are shown in Table 3 .

Table 3 Critical load of truss.

\begin{tabular}{|c|c|c|c|c|c|c|c|}
\hline \multicolumn{2}{|c|}{ Method } & \multicolumn{2}{|c|}{ Model 1} & \multicolumn{2}{|c|}{ Model 2} & \multicolumn{2}{|c|}{ Model 3} \\
\hline \multicolumn{2}{|c|}{ Southwell (separated, upper chord) } & \multicolumn{2}{|c|}{0.9713} & \multicolumn{2}{|c|}{0.9684} & \multicolumn{2}{|c|}{0.9779} \\
\hline \multicolumn{2}{|c|}{ Southwell (whole truss) } & \multicolumn{2}{|c|}{0.9654} & \multicolumn{2}{|c|}{0.9673} & \multicolumn{2}{|c|}{0.9704} \\
\hline \multicolumn{2}{|c|}{ Massey } & \multirow{2}{*}{0.979} & \multirow{2}{*}{1.011} & \multirow{2}{*}{0.987} & \multirow{2}{*}{1.003} & \multirow{2}{*}{0.976} & \multirow{2}{*}{1.034} \\
\hline$\left(\delta / M^{2} ; \delta\right)$ & $\left(\phi / M^{2} ; \phi\right)$ & & & & & & \\
\hline \multicolumn{2}{|c|}{ Trahair } & \multirow{2}{*}{0.950} & \multirow{2}{*}{1.005} & \multirow{2}{*}{0.953} & \multirow{2}{*}{0.974} & \multirow{2}{*}{0.965} & \multirow{2}{*}{1.012} \\
\hline$(M \delta ; \delta)$ & $(M \phi ; \phi)$ & & & & & & \\
\hline \multicolumn{2}{|c|}{ Meck } & \multicolumn{2}{|c|}{0.983} & \multicolumn{2}{|c|}{0.970} & \multicolumn{2}{|c|}{0.988} \\
\hline
\end{tabular}

Comparing the obtained results, it should be recognized, that all the methods presented at the beginning of the paper allow to properly determine the critical load on the truss due to the lateral-torsional buckling (buckling of the compression belt). The differences between the respective average values and the value obtained on the basis of the numerical analysis do not exceed $10 \%$. The average value obtained of all experimental results is 0.981 $\mathrm{kN}$, while the maximum deviation from the average value is $5.4 \%(1.034 \mathrm{kN}$ - Massey model 3 - coordinate system $\left.\phi / M^{2} ; \phi\right)$. 


\section{Analysis of results and conclusions}

The article compares the methods of graphical determination of the critical load on the basis of experimental data. The best-known methods and results of the author's experimental tests are presented. Based on the obtained results, the critical load was determined according to the rules each of the described method. Selected methods are presented in the form of graphical plots. The conducted analysis and obtained results allow for the following conclusions:

- The possibility of applying graphical methods, dedicated to beam elements (Massey, Trahair. Meck) to determine the critical load of a planar truss (in the case of the analyzed static scheme) confirms the validity of the use of the term "lateral-torsional buckling of the truss".

- The critical load values calculated on the basis of plots based on the torsion (Massey and Trahair method) are greater than their counterparts calculated on the basis of the horizontal displacement of the truss. This situation may result from neglecting the influence of the vertical displacement of each belt on twisting of the truss.

- Due to small differences between the numerical and experimental value of the critical load for all methods, it can be assumed that for the purposes of engineering practice, these methods can be used interchangeably.

- It can also be assumed that the analysis of the equilibrium path of a separate upper chord is sufficient to assess the critical load of an entire truss structure.

\section{References}

1. PN-EN 1993-1-1:2006 Eurocode 3: Design of steel structures. Part 1-1: General rules and rules for building [in Polish]

2. S.P. Timoshenko, J.M. Gere, Theory of elastic stability, Arkady, Warszawa (1963)

3. T.V. Galambos, A.E. Surovek, Structural stability of steel: Concepts and applications for structural engineers, John Wiley and son. New Jersey (2008)

4. W.F. Chen, E.M. Lui, Structural stability: Theory and implementation, Elsevier (1987)

5. P. Mandal, C.R. Calladine, Lateral-torsional buckling of beams and the Southwell plot, International Journal of Mechanical Sciences, 44, 2557-2571 (2002)

6. I. Kalkan, Application of Southwell Method on the analysis of lateral torsional buckling tests on reinforced concrete beams, International Journal of Engineering Research and Development, 2, 58-66 (2010)

7. M. Giżejowski, R. Szczerba, M. Gajewski, Influence of imperfections on LTB resistance of steel rolled and welded beams, Journal of Civil Engineering. Environment and Architecture, 3(1), 447-460 (2017)

8. H. Mehri, R. Crocetti, P.J. Gustafsson, Unequally spaced lateral bracings on compression flanges of steel girders, Structures, 3, 236-243 (2015)

9. S.V. Smyrnaios, A. Iliopoulos, I. Vayas, Truss models for inelastic stability analysis and design of steel plate girders, Engineering Structures, 105, 165-173 (2015)

10. M. Piątkowski, Elastic lateral buckling of steel truss with imperfections, Materiały Budowlane, 8, 82-83 (2016) [in Polish]

11. SOFiSTiK - Structural Desktop: User interface of SOFiSTiK software. SOFiSTiK AG. (2008) 